\title{
Refeeding syndrome influences outcome of anorexia nervosa patients in intensive care unit: an observational study
}

\author{
Marie Vignaud ${ }^{1,2}$, Jean-Michel Constantin ${ }^{1,2^{*}}$, Marc Ruivard ${ }^{2,3}$, Michele Villemeyre-Plane ${ }^{4,2}$, Emmanuel Futier $^{1}$, \\ Jean-Etienne Bazin ${ }^{1}$, Djillali Annane ${ }^{5}$, for the AZUREA group (AnorexieRea Study Group) ${ }^{1}$
}

\begin{abstract}
Introduction: Data on the epidemiology and management of anorexia nervosa (AN) in the intensive care unit (ICU) are scarce. The aim of this study was to evaluate the prevalence and associated morbidity and mortality of AN in French ICUs.

Methods: We randomly selected 30 ICUs throughout France. Thereafter, we retrospectively analyzed all patients with AN admitted to any of these 30 ICUs between May 2006 and May 2008. We considered demographic data, diagnosis at admission and complications occurring during the stay, focusing on refeeding syndrome and management of refeeding.

Results: Eleven of the 30 ICUs participated in the retrospective study, featuring 68 patients, including 62 women. Average body mass index at the admission was $12 \pm 3 \mathrm{~kg} / \mathrm{m} 2$. Twenty one were mechanically ventilated, mainly for neurological reasons. The reported average calorie intake was $22.3 \pm 13 \mathrm{kcal} / \mathrm{kg} / 24 \mathrm{~h}$. Major diagnoses at admission were metabolic problems, refeeding survey and voluntary drug intoxication and infection. The most common complications were metabolic, hematological, hepatic, and infectious events, of which 10\% occurred during refeeding. Seven patients developed refeeding syndrome. At day one, the average calorie intake was higher for patients who developed refeeding syndrome $(23.2 \pm 5 \mathrm{Kcal} / \mathrm{kg} / \mathrm{j} ; n=7)$ versus patients without refeeding syndrome $(14.1 \pm 3 \mathrm{Kcal} / \mathrm{kg} / \mathrm{j} ; n=61) P=0.02$. Seven patients died, two from acute respiratory distress syndrome and five from multiorgan-failure associated with major hydroelectrolytic problems.

Conclusions: The frequency of AN in ICU patients is very low and the crude mortality in this group is about $10 \%$. Prevention and early-detection of refeeding syndrome is the key point.
\end{abstract}

\section{Introduction}

The American Psychiatric Association definition of anorexia nervosa (AN) includes refusal to maintain body weight at or above a minimum normal weight for age and size, an intense fear of gaining weight or becoming large when weight is below normal, alteration of perception of body weight or shape, and amenorrhea in postpubertal women. The disease affects $0.5 \%$ of the population and $90 \%$ of patients are women. AN has the highest mortality of any psychiatric disorder [1]. There

\footnotetext{
* Correspondence: jmconstantin@chu-clermontferrand.fr 'General ICU, Estaing Hospital, University Hospital of Clermont-Ferrand, 1 Place Lucie Aubrac, 63000 Clermont-Ferrand, France Full list of author information is available at the end of the article
}

are two types of AN. The pure restrictive form, with physical hyperactivity, accounts for $70 \%$ of patients, and the bulimic form, featuring forced vomiting, affects $30 \%$ of patients. The physiopathology of AN has not yet been fully determined, and may involve genetic, neurobiological, and environmental factors [2,3]. AN is a serious psychiatric disease with severe medical complications, including a mortality rate of $5.6 \%$ per decade from illness, 12 -fold that expected for similar age- and gender-matched groups [4-6]. Hospital admission remains strongly correlated with poor outcome [7]. Brief hospital admission to an acute medical ward or an intensive care unit (ICU) at times of life-threatening crises, or after weight-loss or drug overdose, may reduce
C Biomed Central 
mortality [8]. However, data on the epidemiology and management of AN in the ICU are scarce. The aim of this study was to evaluate frequency of anorexic patients admitted in ICU, and to evaluate complications occurring during ICU stay and patients' outcome, focusing on nutritional management.

\section{Materials and methods}

The study protocol was approved by our local Ethics Committee, and the requirement for informed consent was waived.

\section{Study design}

We randomly selected 30 ICUs using the CEGEDIM list of medico-surgical and medical ICUs $(n=360)$ in France. Next, we included all patients suffering from AN admitted to participating ICUs during the last two years, in an observational study.

\section{Patient selection and data extraction}

We included all patients with AN fulfilling the criteria of the American Psychiatric Association admitted to any of the 30 participating ICUs from May 2006 to May 2008 [1]. There were no exclusion criteria.

We recorded demographic and anthropometric data on ICU admission, any relevant medical history (including age at AN diagnosis and any suicide attempts), and the reason for admission. We searched any complications occurring during an ICU stay. Anemia, leucopenia and thrombopenia were defined by blood cell count below $10 \mathrm{~g} / \mathrm{dL}$, leucocyte count below $1.4 \mathrm{G} / \mathrm{L}$, and platelets count below $150 \mathrm{G} / \mathrm{L}$. Coagulation disorders were defined by prothrombin rate below $60 \%$, or ACT superior to twice the witness. Hypothyroidism was defined by TSH rate above $5 \mathrm{mU} / \mathrm{ml}$. Acute kidney failure was diagnosed when creatinine clearance was below $60 \mathrm{ml} /$ minute. Hepatitis cytolysis was defined by transaminase increasing to three times the normal. Acute lung injury was defined by $\mathrm{PaO}_{2} / \mathrm{F}_{\mathrm{I}} \mathrm{O}_{2}$ ratio between 200 and 300 , and acute respiratory distress syndrome by $\mathrm{PaO}_{2} / \mathrm{F}_{\mathrm{I}} \mathrm{O}_{2}$ below 200, both in ventilated patients. We also recorded vital signs, any need for life-support therapy, feeding modality (route and average intake), any iatrogenic event, crude mortality, and length of ICU stay. We particularly focused on the possible existence of refeeding syndrome, defined by all adverse events occuring during nutritional rehabilitation of malnourished patients or having undergone a prolonged fast [9].

\section{Statistical analysis}

The data were entered into a spreadsheet (Microsoft Excel within Microsoft Office 2007; Microsoft Corp., Redmond, WA, USA). Data are expressed as frequencies for nominal variables, and as means \pm standard deviations (SDs) for continuous variables. Student $t$ test was used for quantitave variables. A $P$-value $<0.05$ was considered statistically significant.

\section{Results}

\section{Retrospective study of anorexic patients}

From May 2006 to May 2008, 68 patients with AN were admitted in 11 of the 30 ICUs. In 19 ICU, no AN patient were admitted in this period. Patient characteristics at baseline are shown in Table 1 . The patients were predominantly female (62 patients), the mean age at the admission was $31 \pm 12$ years, and of very low body mass index $\left(12 \pm 3 \mathrm{~kg} / \mathrm{m}^{2}\right)$. The main reasons for admission were profound metabolic abnormalities or the need to monitor vital signs during refeeding (Figure 1). The other reasons were refeeding survey, voluntary drug intoxication, and infections. During an ICU stay, the most common complications were acute kidney failure in 19 patients (30\%), and metabolic abnormalities like hypophosphatemia in 10 patients $(16 \%)$ or hypokaliemia in 15 patients $(24 \%)$. Hepatic dysfunction, either hepatitis cytolysis or hepatic insufficiency were found in 13 (21\%) and 4 (6\%) patients. Respiratory tract infections with acute lung injury and acute respiratory distress syndrome were developed in six patients (8\%). Diffuse

\section{Table 1 Baseline characteristics of the patients}

\begin{tabular}{|c|c|}
\hline Characteristic & Data \\
\hline \multicolumn{2}{|l|}{ Demographics } \\
\hline Number of patients, $n$ & 68 \\
\hline Female gender, $n$ & 62 \\
\hline Age (years) & $31 \pm 12$ \\
\hline Body mass index $\left(\mathrm{kg} / \mathrm{m}^{2}\right)$ & $12 \pm 3$ \\
\hline \multicolumn{2}{|l|}{ History of anorexia nervosa } \\
\hline Age at onset of illness (years) & $12.7 \pm 3$ \\
\hline Antecedent suicide attempts, $n$ & 10 \\
\hline Patients receiving psychiatric treatment, $n$ & 33 \\
\hline \multicolumn{2}{|l|}{ ICU stay } \\
\hline Length of stay (days) & $7.6 \pm 11$ \\
\hline Tracheal intubation, $n$ & 21 \\
\hline Duration of tracheal intubation, days & $5.3 \pm 6$ \\
\hline \multicolumn{2}{|l|}{ ICU admission from: } \\
\hline Home, $n$ & 36 \\
\hline Medical ward, $n$ & 21 \\
\hline Psychiatric ward, $n$ & 10 \\
\hline Surgical ward, $n$ & 1 \\
\hline \multicolumn{2}{|l|}{ Destination on leaving the ICU: } \\
\hline Home, $n$ & 8 \\
\hline Medical ward, $n$ & 42 \\
\hline Psychiatric ward, $n$ & 9 \\
\hline Surgical ward, $n$ & 2 \\
\hline Deceased, $n$ & 7 \\
\hline
\end{tabular}

ICU: Intensive care unit 


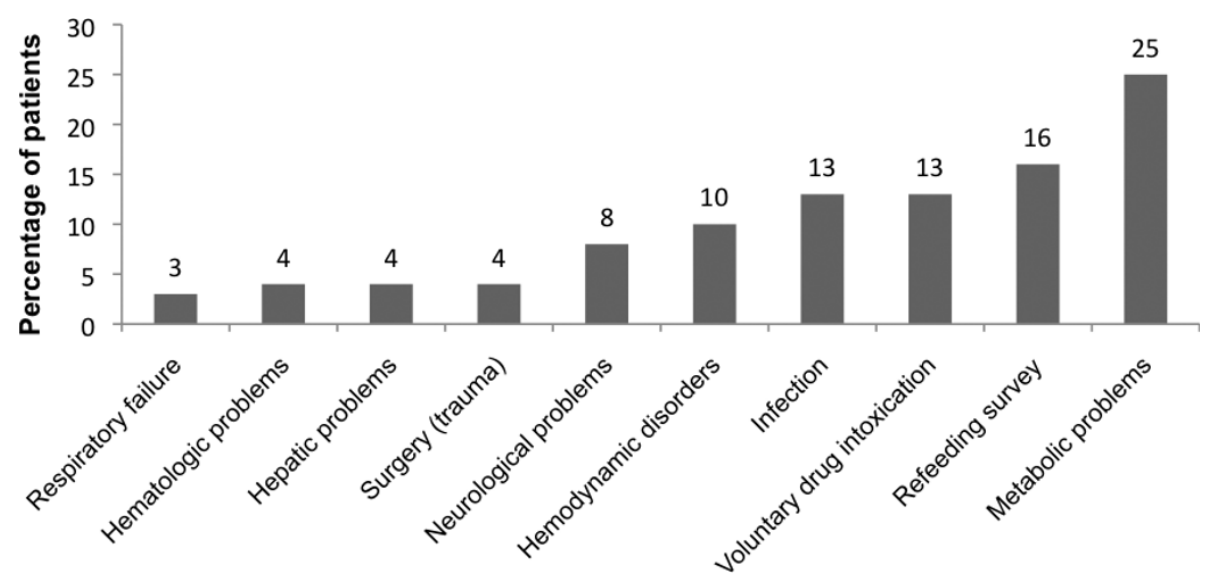

Figure 1 Reasons for admission to the ICU. The reason for admission was the main diagnosis at admission. No associated diagnosis was considered. Data are expressed as percentages of patients.

Table 2 Complication during ICU stay

\begin{tabular}{|c|c|}
\hline Complication & Number of patients \\
\hline \multicolumn{2}{|l|}{ Hematological } \\
\hline Anemia, leukopenia, thrombopenia, $n(\%)$ & $19(30)$ \\
\hline Coagulation disorders, $n$ (\%) & $5(7)$ \\
\hline \multicolumn{2}{|l|}{ Endocrinological } \\
\hline Hypothyroidism, $n$ (\%) & $2(3)$ \\
\hline Isolated hypothermia, $n(\%)$ & $4(6)$ \\
\hline Insipidus diabetes, n (\%) & $2(3)$ \\
\hline \multicolumn{2}{|l|}{ Neurological } \\
\hline Vigilance disorders, $n$ (\%) & $7(10)$ \\
\hline Agitation, $n(\%)$ & $4(6)$ \\
\hline Convulsions, $n(\%)$ & $2(3)$ \\
\hline \multicolumn{2}{|l|}{ Metabolic } \\
\hline Acute kidney failure, $n(\%)$ & $19(30)$ \\
\hline Hypophosphatemia, $n$ (\%) & $10(16)$ \\
\hline Hypokaliemia, $n(\%)$ & $15(24)$ \\
\hline Hyponatremia, n (\%) & $4(6)$ \\
\hline Metabolic alkalosis, n (\%) & $6(8)$ \\
\hline Metabolic acidosis, $n$ (\%) & $3(4)$ \\
\hline Hypoglycemia, $n$ (\%) & $5(7)$ \\
\hline \multicolumn{2}{|l|}{ Cardiovascular } \\
\hline Repolarisation problems, $n$ (\%) & $10(16)$ \\
\hline Bradycardia, $n(\%)$ & $5(7)$ \\
\hline Thromboembolic events, $n$ (\%) & $2(3)$ \\
\hline Hypotension, $n(\%)$ & $8(12)$ \\
\hline Cardiac insufficiency, $n$ (\%) & $3(4)$ \\
\hline \multicolumn{2}{|l|}{ Digestive } \\
\hline Hepatitis cytolysis, n (\%) & $13(21)$ \\
\hline Hepatic insufficiency, $n$ (\%) & $4(6)$ \\
\hline Acute pancreatitis, $n(\%)$ & $2(3)$ \\
\hline \multicolumn{2}{|l|}{ Respiratory track infection } \\
\hline Acute lung injury, $n$ (\%) & $6(8)$ \\
\hline Acute respiratory distress syndrome, $n(\%)$ & $6(8)$ \\
\hline
\end{tabular}

ICU: Intensive care unit abnormal ST segment or $\mathrm{T}$ waves were the most common cardiac complications, reflecting repolarization problems in 10 patients (16\%) (Table 2). There were seven instances of pneumothorax associated with central venous catheterization (69 catheters/61 patients). All catheters were inserted in subclavian, without the use of ultrasound for puncture guidance.

During refeeding, the average calorie intake was $22.3 \pm$ $13 \mathrm{kcal} / \mathrm{kg} / 24 \mathrm{~h}$. In 30 patients (44\%), full calorie intake was initiated on the first day of refeeding. Refeeding was complicated in seven patients, including three patients with major hypophosphatemia and associated hemodynamic disorders, two patients with acute pancreatitis, one patient with cardiac arrest, and one patient with tetraplegia. At day one, the average calorie intake was higher for the patients who developed refeeding syndrome $(23.2 \pm 5 \mathrm{Kcal} / \mathrm{kg} / \mathrm{j} ; n=$ 7) versus patients without refeeding syndrome (14.1 \pm 3 $\mathrm{Kcal} / \mathrm{kg} / \mathrm{j} ; n=61) P=0.02$. There was no difference in the average intake during ICU stay. The mortality rate was $71 \%$ (5 of 7) for patients with refeeding syndrome and 3\% (2 of 61 ) for patients without the syndrome $(P<0.001)$. All patients with suspected refeeding syndrome required mechanical ventilation. In six of the seven patients with suspected refeeding syndrome, mechanical ventilation was initiated after refeeding commenced. Twenty-one patients required invasive mechanical ventilation. This was due to neurologic disorders in 12 patients and hypoxic respiratory failure in 9 patients. Seven patients died, two from refractory hypoxemia and five from multiple organ failure subsequent to major metabolic disorders and hepatic cytolysis following initiation of nutrition support. Prealbumin concentration was measured in 26 patients (38\%).

\section{Discussion}

The main findings of this study are that the prevalence of patients with AN in ICUs is very low and the crude 
mortality is about $10 \%$. Particularly, inappropriate nutritional support was associated with a high prevalence of refeeding syndrome. On average, patients received a total calorie intake of $22 \pm 13 \mathrm{kcal} / \mathrm{kg} / 24 \mathrm{~h}$.

The recent UK NICE (National Institute for Health and Clinical Excellence) guidelines suggested that calorie repletion in AN patients should be slow, and should depend on the assessed severity of refeeding syndrome risk [10]. For patients at high risk, the initial nutritional level should be approximately $10 \mathrm{kcal} / \mathrm{kg} / \mathrm{d}$, falling to as low as $5 \mathrm{kcal} / \mathrm{kg} / \mathrm{d}$ in patients considered to be at extreme risk. A gradual increase in calorie intake, particularly during the first week of refeeding, in combination with regular biochemical and fluid balance monitoring, is important until a patient becomes metabolically stable.

Unsurprisingly, refeeding induced metabolic disorders and hepatic cytolysis in 10 to $20 \%$ of AN patients. The mean risk factors are AN per se, the classic forms of slump, and malnutrition related to chronic disease. Only a few studies have analyzed the incidence of refeeding syndrome in the ICU. In a prospective study, serum prealbumin concentration was the only biomarker predictive of the development of refeeding syndrome [11]. In the present study, prealbumin levels were recorded only in a third of the cases. In our retrospective study, full calorie intake was initiated on the first day of refeeding in about half of AN patients. In patients for whom calorie intake was gradually increased, physicians did not adequately appreciate the evidence of refeeding syndrome, as shown by biological abnormalities, in seven patients. In five patients, refeeding resulted in multi-organ failure and death, although nutrition was stopped. Refeeding syndrome can be defined as a potentially fatal shift in fluid and electrolyte levels that may occur in malnourished patients receiving artificial nutrition (whether enteral or parenteral) [12]. All of oral, enteral, and parenteral feeding routes were used in our study. Most experts agree that oral refeeding is the best approach to weight restoration. In situations in which patients refuse to eat, or in patients with extreme malnutrition, feeding via a nasogastric tube may be required [13]. If the digestive tract is functional, the enteral route is preferable to the parenteral even though parenteral nutrition can be safe and efficient $[14,15]$.

As previously described [16], the observed prevalence of pneumothorax after central venous catheterization was six percent, approximately twice that usually observed in ICU patients [17]. To reduce the risk of this condition, we propose that an internal jugular site, and not a subclavian site, be used, with ultrasound guidance [18]. This proposal should be tempered by the infectious complications rate reported with that site [19].
The current recommendations for diagnostic investigation and monitoring in AN patients admitted to psychiatric and medical units may be inappropriate for ICU patients [20]. In our study, the high incidence of cardio vascular complications, particulary hypotension and repolarization problems, suggest that electrocardiography and echocardiography should be routinely performed at the admission of AN patients. In fact, in many publications a high incidence of occult left ventricular failure and pericardial effusion was reported in such patients [21]. In addition, improvement in cardiac function upon renutrition may be a good index of the quality of nutritional support. Metabolic disorders were the main reason for ICU admission. These disorders are the best-known metabolic complications in AN patients, and are caused by starvation or purgative practices. Profound hypoglycemia usually recurred after glucose administration, as a consequence of pathologic hyperinsulinism, and was associated with poor prognosis [22]. Hypokalemia, hyponatremia, hypomagnesemia, and metabolic alkalosis are associated with purgative practices or diuretic abuse. Hypophosphatemia was less often reported, although this is the most common sign of refeeding syndrome. As suggested, detection and correction of hypophosphatemia should be systematic at ICU admission of AN patients and before refeeding [23]. The second most common reason for ICU admission was nutritional support. When the body mass index is less than $12 \mathrm{~kg} / \mathrm{m}^{2}$, resting energy expenditure is only 60 to $65 \%$ of normal levels [13]. During refeeding, this expenditure increases significantly. Thus, it is a challenge for physicians to find a compromise between low nutritional input, with the risk of insufficient weight gain, and higher nutritional input, causing refeeding syndrome. Hemodynamic and electrocardiographic disorders were also common reasons for ICU referral. Hepatic cytolysis in AN patients was reported by $20 \%$ of physicians. Several studies and case reports have highlighted increases in serum liver enzymes in patients with AN or extreme malnutrition, whether or not associated with liver failure $[24,25]$. AN, and malnutrition in general, can be linked to neurological disorders such as psychomotor slowing, memory difficulties, and disorientation, that are generally reversible after renutrition [26]. Hematological disorders include leukoneutropenia, associated with bone marrow gelatinous degeneration macrocytic anemia, secondary to intra-erythrocytic ATP deficiency and thrombocytopenia $[27,28]$. Moreover, in patients with AN, a reduction in the contractile force of the diaphragm, and alteration in the regulation of respiratory centers, may induce respiratory failure.

Nineteen percent of patients had pneumonia and nine percent had acute respiratory distress syndrome. In vitro 
studies have suggested that starvation may be associated with altered cellular and humoral immunity $[29,30]$. Immune suppression during AN may also involve abnormal responses of the complement system and hypercorticism.

\section{Conclusions}

Anorexia nervosa is an infrequent cause of ICU admission. Iatrogenia influences outcome of these young patients. Early recognition and prevention of refeeding syndrome is a key issue in ICU management of such patients.

\section{Key messages}

- Anorexia nervosa is an infrequent cause of ICU admission.

- ICU physicians need recommendations to improve the management of anorexia nervosa patients.

- Early recognition and prevention of refeeding syndrome is a major issue.

- Prevention of iatrogenic events may decrease mortality of anorexia nervosa patients admitted in ICU.

\section{Abbreviations}

AN: anorexia nervosa; ICU: intensive care unit

\section{Acknowledgements}

The authors thank Dr Scott Butler for English editing, Dr JP Mission for statistical analysis, and Marie Christine Bonnaud for study administration. They also thank the members of the AnorexieRea study group for their contributions. This work has been supported by, and should be attributed to, the University Hospital of Clermont-Ferrand, Clermont-Ferrand, France. This work has been presented in part in the French Society of Anesthesiology and Critical Care médicine, Paris, September 2009.

\section{AnorexieRea study group}

Sophie Cayot Constantin, General ICU, Estaing Hospital, University Hospital of Clermont-Ferrand, Clermont-Ferrand, France.

Renaud Guerin, General ICU, Estaing Hospital, University Hospital of Clermont-Ferrand, Clermont-Ferrand, France.

Matthieu Jabaudon, General ICU, Estaing Hospital, University Hospital of

Clermont-Ferrand, Clermont-Ferrand, France.

Christian Chartier, General ICU, Estaing Hospital, University Hospital of Clermont-Ferrand, Clermont-Ferrand, France.

Sebastien Perbet, General ICU, Estaing Hospital, University Hospital of Clermont-Ferrand, Clermont-Ferrand, France.

Antoine Petit, General ICU, Estaing Hospital, University Hospital of ClermontFerrand, Clermont-Ferrand, France.

Samir Jaber, SAR B, Saint Eloi Hospital, university Hospital of Montpellier, Montpellier, France.

Gerald Chanques, SAR B, Saint Eloi Hospital, university Hospital of Montpellier, Montpellier, France.

Philippe Verdier, General ICU, Montlucon Hospital, Montlucon, France. Robert Chausset, General ICU, Montlucon Hospital, Montlucon, France. Dominique Guelon, RMC, University Hospital of Clermont-Ferrand, Clermont-Ferrand, France.

Claude Guerin, Medical ICU, La croix rousse, Lyon university Hospital, Lyon, France

Laurent Papazian, Medical ICU, APHM, Marseille, France.

Jean Paul Mira, Medical ICU, Cochin, APHP, Paris V University, France. Bernard Blettery, Medical ICU, Dijon university Hospital, Dijon, France. Bernard Claud, General ICU, Le Puy en velay Hospital, Le Puy en velay, France.

Jean Yves Lefrant, General ICU, Nimes University Hospital, Nimes, France.
Jean Michel Arnal, Medical ICU, Toulon Hospital, Toulon, France. Carole Ichai, Surgical ICU, Nice University Hospital, Nice, France. Olivier Leroy, Genera ICU, Tourcoing Hospital, Tourcoing, France. Benoît Valet, General ICU, University hospital of Lille, Lille, France. Olivier Pajot, General ICU, Argenteuil Hospital, Argenteuil, France. Bernard Garrigues, General ICU, Aix en provence Hospital, Aix-en-provence Hospital, France.

\section{Competing interests}

The authors declare that they have no competing interests.

\section{Authors' contributions}

MV and JMC participated in the design of the study, carried out the study and drafted the manuscript. MR, MVP, EF and JEB participated in the design of the study and data analysis. DA participated in the design of the study and helped to draft the manuscript. All authors read and approved the final manuscript.

\section{Author details}

${ }^{1}$ General ICU, Estaing Hospital, University Hospital of Clermont-Ferrand, 1 Place Lucie Aubrac, 63000 Clermont-Ferrand, France. ${ }^{2}$ Auvergne Anoria Network, University Hospital of Clermont-Ferrand, 1 Place Lucie Aubrac, 63000 Clermont-Ferrand, France. ${ }^{3}$ Internal medicine department, Estaing Hospital, University Hospital of Clermont-Ferrand, 1 Place Lucie Aubrac, 63000 Clermont-Ferrand, France. ${ }^{4}$ Centre medico-psychiatrique B, University Hospital of Clermont-Ferrand, 1 Place Lucie Aubrac, 63000 Clermont-Ferrand, France. ${ }^{5}$ General Intensive Care Unit, Raymond Poincare Hospital (AP-HP), University of Versailles, SQY, 104 Boulevard Raymond Poincare, 92380 Garches, France.

Received: 26 April 2010 Revised: 2 July 2010

Accepted: 28 September 2010 Published: 28 September 2010

\section{References}

1. Hoek HW, van Hoeken D: Review of the prevalence and incidence of eating disorders. Int J Eat Disord 2003, 34:383-396.

2. Walsh BT, Kaplan AS, Attia E, Olmsted M, Parides M, Carter JC, Pike KM, Devlin MJ, Woodside B, Roberto CA, Rockert W: Fluoxetine after weight restoration in anorexia nervosa: a randomized controlled trial. JAMA 2006, 295:2605-2612.

3. Fairburn CG, Cowen PJ, Harrison PJ: Twin studies and the etiology of eating disorders. Int J Eat Disord 1999, 26:349-358.

4. Miller JJ 3rd, Ammerman S, Parker BR: Anorexia nervosa presenting as a peripheral vasculopathy in an adolescent male. J Rheumatol 1995, 22:544-547.

5. Steinhausen HC: The outcome of anorexia nervosa in the 20th century. Am J Psychiatry 2002, 159:1284-1293.

6. Zipfel S, Lowe B, Reas DL, Deter HC, Herzog W: Long-term prognosis in anorexia nervosa: lessons from a 21-year follow-up study. Lancet 2000, 355:721-722

7. Ben-Tovim DI, Walker K, Gilchrist P, Freeman R, Kalucy R, Esterman A: Outcome in patients with eating disorders: a 5-year study. Lancet 2001, 357:1254-1257.

8. Lowe B, Zipfel S, Buchholz C, Dupont Y, Reas DL, Herzog W: Long-term outcome of anorexia nervosa in a prospective 21-year follow-up study. Psychol Med 2001, 31:881-890.

9. Mehanna HM, Moledina J, Travis J: Refeeding syndrome: what it is, and how to prevent and treat it. BMJ 2008, 336:1495-1498.

10. National Institute for Health and Clinical Excellence: Nutrition support in adults: full guideline (CG32).[http://www.nice.org.uk/nicemedia/live/10978/ 29981/29981.pdf].

11. Marik PE, Bedigian MK: Refeeding hypophosphatemia in critically ill patients in an intensive care unit. A prospective study. Arch Surg 1996, 131:1043-1047.

12. Solomon SM, Kirby DF: The refeeding syndrome: a review. JPEN J Parenter Enteral Nutr 1990, 14:90-97.

13. Rigaud D, Brondel L, Poupard AT, Talonneau I, Brun JM: A randomized trial on the efficacy of a 2-month tube feeding regimen in anorexia nervosa: A 1-year follow-up study. Clin Nutr 2007, 26:421-429.

14. Pertschuk MJ, Forster J, Buzby G, Mullen JL: The treatment of anorexia nervosa with total parenteral nutrition. Biol Psychiatry 1981, 16:539-550. 
15. Diamanti A, Basso MS, Castro M, Bianco G, Ciacco E, Calce A, Caramadre AM, Noto C, Gambarara M: Clinical efficacy and safety of parenteral nutrition in adolescent girls with anorexia nervosa. $J$ Adolesc Health 2008, 42:111-118.

16. Cartwright MM: Eating disorder emergencies: understanding the medical complexities of the hospitalized eating disordered patient. Crit Care Nurs Clin North Am 2004, 16:515-530.

17. McGee DC, Gould MK: Preventing complications of central venous catheterization. N Engl J Med 2003, 348:1123-1133.

18. Lichtenstein D, Saifi R, Augarde R, Prin S, Schmitt JM, Page B, Pipien I, Jardin F: The Internal jugular veins are asymmetric. Usefulness of ultrasound before catheterization. Intensive Care Med 2001, 27:301-305.

19. Raad I: Intravascular-catheter-related infections. Lancet 1998, 351:893-898.

20. Morris J, Twaddle S: Anorexia nervosa. BMJ 2007, 334:894-898.

21. Lupoglazoff JM, Berkane N, Denjoy I, Maillard G, Leheuzey MF, MourenSimeoni MC, Casasoprana A: [Cardiac consequences of adolescent anorexia nervosa]. Arch Mal Coeur Vaiss 2001, 94:494-498.

22. Inui A, Uemoto M, Seki W, Ueno N, Morita S, Baba S, Kasuga M: Rebound hypoglycaemia after intravenous glucose in anorexia nervosa. Lancet 1996, 347:323-324.

23. Zazzo JF, Troche G, Ruel P, Maintenant J: High incidence of hypophosphatemia in surgical intensive care patients: efficacy of phosphorus therapy on myocardial function. Intensive Care Med 1995, 21:826-831.

24. Mickley D, Greenfeld D, Quinlan DM, Roloff P, Zwas F: Abnormal liver enzymes in outpatients with eating disorders. Int J Eat Disord 1996, 20:325-329.

25. Tsukamoto M, Tanaka A, Arai M, Ishii N, Ohta D, Horiki N, Fujita Y: Hepatocellular injuries observed in patients with an eating disorder prior to nutritional treatment. Intern Med 2008, 47:1447-1450.

26. Kerem NC, Katzman DK: Brain structure and function in adolescents with anorexia nervosa. Adolesc Med 2003, 14:109-118.

27. Nishio S, Yamada H, Yamada K, Okabe H, Okuya T, Yonekawa O, Ono T, Sahara N, Tamashima S, Ihara M: Severe neutropenia with gelatinous bone marrow transformation in anorexia nervosa: a case report. Int J Eat Disord 2003, 33:360-363.

28. Kaiser $\mathrm{U}$, Barth $\mathrm{N}$ : Haemolytic anaemia in a patient with anorexia nervosa. Acta Haematol 2001, 106:133-135.

29. Marcos A: The immune system in eating disorders: an overview. Nutrition 1997, 13:853-862.

30. Pomeroy C, Eckert E, Hu S, Eiken B, Mentink M, Crosby RD, Chao CC: Role of interleukin- 6 and transforming growth factor-beta in anorexia nervosa. Biol Psychiatry 1994, 36:836-839.

doi:10.1186/cc9274

Cite this article as: Vignaud et al:: Refeeding syndrome influences outcome of anorexia nervosa patients in intensive care unit: an observational study. Critical Care, 2010, 14:R172.

\section{Submit your next manuscript to BioMed Central and take full advantage of:}

- Convenient online submission

- Thorough peer review

- No space constraints or color figure charges

- Immediate publication on acceptance

- Inclusion in PubMed, CAS, Scopus and Google Scholar

- Research which is freely available for redistribution

Submit your manuscript at www.biomedcentral.com/submit
Biomed Central 